\title{
Follow up care of bereaved parents after treatment withdrawal from newborns
}

\author{
H E McHaffie, I A Laing, D J Lloyd
}

\begin{abstract}
Objective-To explore parents' experiences of bereavement care after withdrawal of newborn intensive care. Design-Face to face interviews with 108 parents of 62 babies born over two calendar years in the East of Scotland.

Results-Only $22 \%$ were seen by six weeks after the death, $10 \%$ were not recalled before 6-11 months, and $8 \%$ were not seen at all in the first year. All except one couple saw the neonatologist who had cared for their baby. Only $33 \%$ remembered a neonatal nurse being present. Most $(88 \%)$ were seen in the study hospital. Parents highlighted a number of specific needs. Appointments should be: $(a)$ scheduled soon after the death of the baby and certainly within two months of the death irrespective of whether or not autopsy results are available; $(b)$ with the named neonatologist; (c) in a setting away from the hospital if possible. Parents value: $(a)$ efforts to find out how they are coping; (b) full frank information given sensitively to enable them to build up a cohesive picture of what happened and assess their future risks; (c) reassurance where possible, but half truths, false reassurances, and broken promises are unacceptable.

Conclusions-Follow up care is a crucial part of the management of families from whose babies treatment has been withdrawn. Resources devoted to it should be re-examined to provide a service more in tune with parental need. In choosing the place, timing, and conduct of the meeting, staff should be sensitive to the expressed wishes of the parents themselves.
\end{abstract}

(Arch Dis Child Fetal Neonatal Ed 2001;84:F125-F128)

Keywords: follow up; treatment withdrawal; bereaved parents; neonatal

An extensive literature exists on parental grief, and a few authors have tried to analyse what is known. ${ }^{1-7}$ What emerges is a consensus view that the death of a child is an exceptionally painful loss to accept and live with. ${ }^{8}$ Responses have been variously correlated with a range of factors including demographic elements, personality, features of the hospitalisation or death, anticipatory grief, marital intimacy, social support, counselling, and early subsequent pregnancy. ${ }^{1-8}$ There is little information, however, on the effect of professional interventions, ${ }^{4}$ and a recent search of the main medical databases found no studies of parents' follow up visits to health care professionals after a perinatal death.

The Stillbirth and Neonatal Death Society (SANDS) has described a follow up visit as "essential" for all women who have lost babies, ${ }^{9}$ and offered some guidance as to timing and setting. However, we could find no evidence on which today's practices are founded. Important questions remain about parents' own needs and experiences. Is four to six weeks the optimal time for recalling them? What are their expectations at this visit? What factors do they find helpful or unhelpful? As part of a larger project looking at the experience of treatment limitation, we investigated parents' perceptions of their follow up care during the first 13 months after the death of their infant. Additional papers are in preparation reporting findings relating to the ethical issues, decision making, and the management of such families.

\section{Method}

SETTING

Three regional neonatal referral centres in the East of Scotland, covering a representative range of populations, were selected as the study units. Ethics committee approval was obtained for each centre.

\section{SAMPLE}

Families were eligible for inclusion if there had been any discussion about withholding/ withdrawing newborn intensive care. The babies were those for whom there was a medical prognosis of either early death or severe impairment associated with a very poor quality of life; all of these infants did indeed die. All three main categories of imperilled babies were represented: preterm delivery, congenital anomalies, asphyxia. Figure 1 gives numbers of eligible and recruited families.

\section{PROCEDURE}

In all three units, the stated policy was to recall parents approximately six weeks after the death. Respondents were recruited at the time of their first follow up clinic appointments, and semistructured interviews (based on the literature, research, and clinical experience) were scheduled to take place three and 13 months after the death of the baby. In practice, delays in follow up appointments influenced the timing of some of the first interviews (fig 2).

Topics under investigation included parents' perceptions of their whole experience of this pregnancy, birth, decision making, death, and first year of bereavement. Interviews lasted from one to five and a quarter hours and were all tape recorded. Data were recorded under predetermined variable names and analysed 


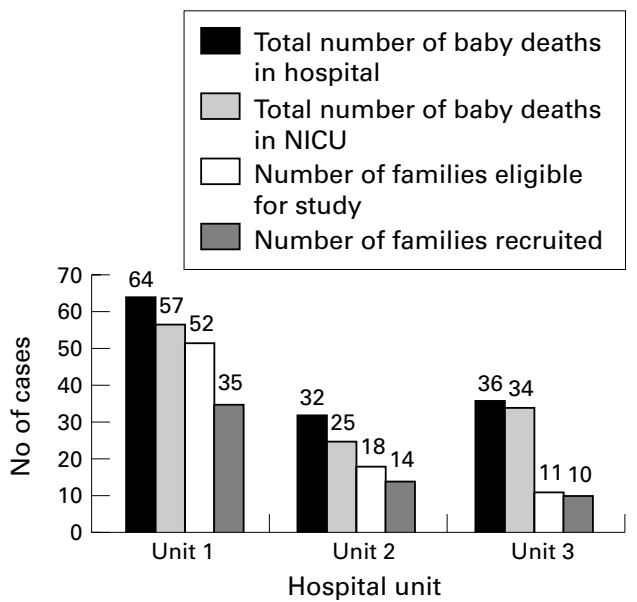

Figure 1 Numbers of baby deaths during the study period and families recruited in each study unit. NICU, neonatal intensive care unit.

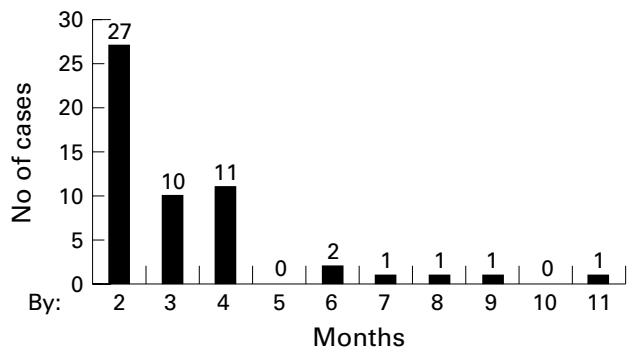

Figure 2 First follow up visit: time after baby's death $(n=54)$.

using SPSS for the Apple Mac. Independent checks for accuracy of coding and interpretation of content were carried out by a practising paediatrician (Dr P W Fowlie; 12\% of interviews) and a student in medical ethics ( $R$ Bercovitch; 10\%).

\section{RESPONDENTS}

During the two year recruitment period, 3398 babies were admitted to the three study units; 116 of these babies died while in the unit. Eighty one families met the eligibility criteria for inclusion in the study. Twenty two eligible families were lost to the enquiry: 11 declined to participate, and 11 were not told about the study because they declined all follow up (six), they could not be contacted (two), they were considered unsuitable for recruiting (one), or unknown reasons (two). No information is available on whether these babies died before or after treatment withdrawal. Analysis of the parental and infant data indicates that, although there were more teenagers and unemployed women in the non-respondent group, our sample was representative of families with babies in neonatal intensive care units in Scotland.

A total of 59 families (108 individuals) participated at three months, and 50 families (90 individuals) at 13 months. Nine were unavailable for second interviews: five could not be traced, three declined, and we were advised by a general practitioner against contacting the remaining family. Tables 1 and 2 give basic data on the families.
Table 1 Details of parents (mothers, $n=59$; fathers, $n=54$ )

\begin{tabular}{ll}
\hline Cohabiting & $91 \%$ \\
Interviewed as a couple & $75 \%$ (1st interview) \\
& $80 \%$ (2nd interview) \\
& \\
Age of mothers & $8 \%$ \\
$\quad<20$ & $32 \%$ \\
$20-29$ & $54 \%$ \\
$30-39$ & $5 \%$ \\
$40+$ & \\
Age of fathers & $33 \%$ \\
$20-29$ & $57 \%$ \\
$30-39$ & $9 \%$ \\
$40+$ & $31 \%$ primigravidae \\
Parity of mothers & $69 \% 1-5$ previous pregnancies \\
& $19 \%$ \\
Previous infertility & $14 \%$ \\
Multiple births &
\end{tabular}

Table 2 Basic data for babies $(n=62)$

\begin{tabular}{ll}
\hline Gestation & \\
$<24$ weeks & $15 \%$ \\
$24-28$ weeks & $40 \%$ \\
$29-40$ weeks & $29 \%$ \\
$40+$ weeks & $16 \%$ \\
Length of life & \\
$\leqslant 1$ week & $61 \%$ \\
$>1$ week-1 month & $15 \%$ \\
$>1-2$ months & $15 \%$ \\
$3-6$ months & $6 \%$ \\
$7-10$ months & $3 \%$ \\
\hline
\end{tabular}

\section{Results}

It is important to note that in two cases the baby deteriorated and died before treatment could be withdrawn, although staff had advocated stopping on several occasions. We could find no indication that these two couples differed from the remaining 57 on any measure under review, so their data have been included.

MISSED BEREAVEMENT CLINIC APPOINTMENTS Most parents $(54 / 59,92 \%)$ attended at least one paediatric follow up bereavement clinic appointment during the first year after the death. Of the five who were not seen, no appointment was offered in two cases where babies had been cared for in a neonatal intensive care unit outside their home area. Attempts had been made to arrange an appointment in three cases but the parents felt there was nothing to be gained from attending, a mutually convenient time could not be found, or the named neonatologist was unavailable when the parents arrived and no further appointment was received.

TIMING OF BEREAVEMENT CLINIC APPOINTMENTS Despite stated policy, in reality only $22 \%$ of the parents were seen by six weeks after the death, $46 \%$ by two months, and $81 \%$ by four months (fig 2). For $10 \%$ the visit was delayed until 6-11 months after the death. Some families postponed visits when they were unready to go back, forgot appointments, or were ill. In the parents' perceptions, hospitals delayed appointments as the result of administrative oversight or because test results were not available. Six sets of parents had taken active measures themselves to bring appointments forward. 


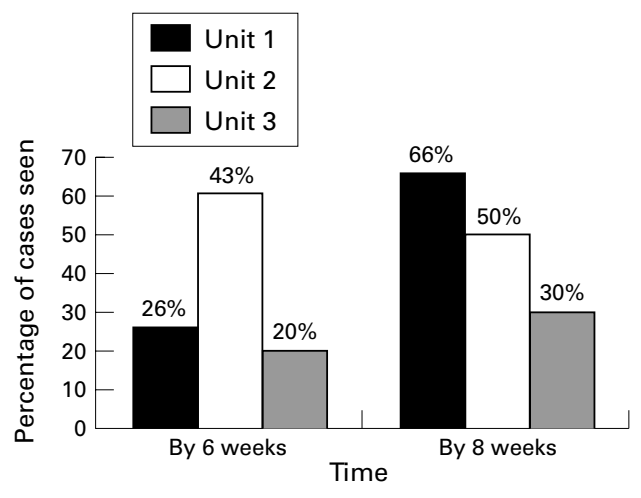

Figure 3 Comparison of follow up times in the study units.

At the first research interview, a quarter of the parents $(15 / 59)$ intended to return for a further follow up meeting with the hospital staff. Three of these 15 were not available for second interview, but of the remaining 12, only three actually went back.

DIFFERENCES BETWEEN UNITS

When the three study units were compared, important differences emerged (fig 3).

Only a quarter of parents in unit 1 and a fifth in unit 3 were seen within six weeks, whereas as many as $43 \%$ were seen within this period in unit 2. By eight weeks, proportionally more than twice as many parents had been seen in unit 1 than in unit 3. Less than a third were seen by this time in unit 3 .

\section{PERSONNEL INVOLVED}

In most cases, couples attended visits to the neonatologist together. Only one mother reported being upset that her partner consistently refused to go with her.

All except one couple saw the named neonatologist who had cared for their baby. By 13 months, most $(48,81 \%)$ had been back just once to see him or her. Seven (12\%) had had joint meetings with the neonatologist and obstetrician. A few parents commented that it had been burdensome to have to go repeatedly for follow up visits-four families had kept three or four separate appointments in the first three months.

Only 18 of the 54 sets of parents (33\%) remembered a neonatal nurse being present. Eight $(14 \%)$ saw a geneticist at some point, one a "high risk specialist", and another a social worker.

\section{THE CONSULTANT'S ROLE}

It was clear that the consultant has a key role in the experience of families when treatment is withdrawn. Four main features were identified as characteristic of good practice: sharing memories and experiences of the child, showing compassion and understanding, communicating effectively, and demonstrating a personal interest.

\section{LOCATION}

Most of the parents visited the neonatologist exclusively in the study hospital $(52 / 59,88 \%)$, most commonly in a small room away from the nursery $(48 / 52,92 \%)$, with only two being seen in the neonatal intensive care unit itself. One mother had felt too distressed to even enter the hospital, and the neonatologist went out to her car. Two sets of parents were seen in their local hospitals.

\section{LENGTH OF MEETINGS}

Taking into account all visits to obstetricians, specialists, and neonatologists, parents remembered sessions as lasting for anything up to two hours. They appreciated an unhurried approach.

\section{HELPFUL FACTORS}

In addition to the factors already discussed, parents identified three elements to follow up that were important: full and frank information which answered their questions and clarified exactly what had happened; reassurance about what had been done, the decision, and future risks; care and respect for the whole family.

\section{Discussion}

The Royal College of Paediatrics and Child Health (RCPCH) framework dealing with treatment withdrawal ${ }^{10}$ gives only a brief mention to follow up care. Our findings show that to parents this is a crucial part of their management which merits strong emphasis, and their insights offer useful practical guidance.

We found potential loopholes in a system for recalling bereaved families. Particular circumstances for vigilance are where babies are transferred out of the area or where one or more siblings survive in multiple births.

Our findings show that most parents prefer to be seen soon after the death. The traditional "postnatal check" time of six weeks has been widely adopted, but preliminary autopsy results can usually be available within two weeks and it has been suggested that this makes a more suitable point to recall such parents. ${ }^{11}$ In more complex cases, postmortem tests are inevitably protracted, but our data indicate that early contact is desirable even in the absence of a full picture as parents search for enough information to piece together a coherent picture of what has happened in order to make progress in their grieving, to assess the risks of recurrence or the genetic implications, and to contemplate another pregnancy. When they are not seen at the promised time, parents can feel abandoned as well as disappointed.

Further appointments may indeed be necessary. However, in reality, although the parents may wish such management, a range of factors may influence a consultant's capacity to offer optimal care-for example, work loads, resources, availability of support from colleagues. It is not necessarily the case that already busy consultants would be overloaded with additional bereavement care work, however, if early intervention is effective. We found that currently very few families take up an open ended invitation to come back at any time after the first scheduled bereavement clinic visit; only five families ( $8 \%$ ) did so. Parents may not need to come back to see the consultant in person to 
obtain test results. Careful assessments of cost benefit ratios, priorities, and commitments need to be made.

Follow up visits have two main purposes and both must be borne in mind when assessing the efficacy of bereavement services. Full and frank information gives power and understanding. ${ }^{12}$ The truth may sometimes be painful but concealment hurts more and undermines trust in both the health care system and professionals within it. ${ }^{12}$ What parents are looking for is an account consistent with the facts they have seen and heard, which they can understand and learn to accept. Emotional support comes from the professional team sharing memories of the child and events in his/her life, thus providing comfort and confirmation.

The RCPCH framework recommends discussing the results of the postmortem examination. Clinicians have suggested that detailed accounts may aid the grieving process. ${ }^{13}$ However, insights from our research caution that some parents find the catalogue of problems or impairments extremely distressing, and the enormity of what has happened too stark to bear. They may need to put the written report away to be read later, or speak to the consultant more than once to piece the story together in bearable instalments. Nevertheless the consistent message parents give is that they do not want sanitised versions of the truth. Reassurance when it comes from an authoritative source is welcomed but not if it is false.

Careful thought needs to be given to the setting for follow up visits. Revisiting the hospital where their child died is a painful journey for parents, a fact spontaneously volunteered by almost half the parents in our study. Obstetricians have suggested that their distress is justification for domiciliary visits. ${ }^{14}$ Having summoned the courage to attend, it is additionally painful to be surrounded by evidence of other successful pregnancies, ${ }^{9}{ }^{12} 13$ to be mistaken for an antenatal couple, or be the butt of tactless or cheerful banter. It is essential that a reliable system of marking the notes of bereaved parents is adopted to avoid such errors. ${ }^{9}$ This research re-affirms the guidance from SANDS to choose a meeting place away from antenatal clinics or the neonatal unit, and a separate time for their visit, ${ }^{11}$ but indicates that their advice is not always heeded.

CONCLUSION

Enormous sums of money and a high quality of compassionate and skilled care are devoted to families in our neonatal intensive care units.
This study has re-affirmed the overall excellence of the service provided, but it has highlighted deficiencies in the aftercare of parents whose babies die after treatment withdrawal.

Until now bereavement care has largely been predicated on an intuitive response to a perceived need. In revealing what the parents themselves find helpful, our research has provided empirical support for some of these intuitive practices but has also highlighted areas for improvement. The staff of neonatal intensive care units have a highly valued role in the experience of these families who live through the trauma of treatment withdrawal and death. The real question is, can the NHS and society resource them in the completion of their task?

We are grateful to many colleagues for their contribution to this project but particularly members of the research team, Mr R Bercovitch, Dr K M Boyd, Professor A G M Campbell, Dr P W Fowlie, Professor R Hume, Dr A J Lyon, and Dr C H M Walker, colleagues in the study units and in the Institute of Medical Ethics. The study was funded by The Scottish Executive. Our greatest debt is to the bereaved parents who so courageously greatest debt is to the bereaved parents
shared their experiences and insights.

1 Oglethorpe RJL. Parenting after perinatal bereavement: a review of the literature. Fournal of Reproductive and Infant Psychology 1989; 7:227-44.

2 Zeanah $\mathrm{CH}$. Adaptation following perinatal loss: a critical review. F Am Acad Child Adolesc Psychiatry 1989;28:46780

3 Neidig JR, Dalgas-Pelish P. Parental grieving and perceptions of health care professionals' interventions. Issues in Comprehensive Pediatric Nursing 1991;14:179-91.

4 Hazzard A, Weston J, Gutterres C. After a child's death: factors related to parental bereavement. F De Behav Pediatr 1992;13:24-30.

5 Braun MJ, Berg DH. Meaning reconstruction in the experience of parental bereavement. Death Studies 1994;182:105-29.

6 Brabant S, Forsyth CJ, McFarlain G. Defining the family after the death of a child. Death Studies 1994;182:197-206.

7 MacGregor P. Grief: The unrecognized parental response to mental illness in a child. Social Work 1994;39:160-6.

8 Rando TA. Parental adjustment to the loss of a child. In: Papadotou D, Papadotos C, eds. Children and death. London: Hemisphere, 1991:233-53.

9 Stillbirth and Neonatal Death Society. Miscarriage, stillbirth and neonatal death: guidelines for professionals. London: SANDS, 1991

10 Fox R, Pillai M, Porter $\mathrm{H}$, et al. The management of late fetal death: a guide to comprehensive care. $\mathrm{Br} \mathcal{F}$ Obstet Gynaecol 1997;104:4-10.

11 Kohner N, Henley A. When a baby dies. The experience of late miscarriage, stillbirth and neonatal death. London: Pandora, 1995.

12 Laing IA, Halley GC. Enough is enough: when to stop neonatal care. Current Paediatrics 1995;5:53-8.

13 Chitty LS, Barnes CA, Berry C. Continuing with pregnancy after a diagnosis of lethal abnormality: experience of five couples and recommendations for management. BMf 1996;313:478-80.

14 Royal College of Paediatrics and Child Health. Withholding or withdrawing life saving treatment in children. A framework for practice. London: RCPCH, 1997. 